\title{
Farklı sulama düzeylerinin pamuk'da verim ve bazı kalite parametreleri üzerine etkisi
}

\section{The effect of different irrigation levels on cotton yield and some quality parameters}

\author{
Yusuf AYDIN \\ Siirt Üniversitesi, Ziraat Fakültesi, Biyosistem Mühendisliği Bölümü, 56100, Siirt \\ Sorumlu yazar (Corresponding author): Y. Aydın, e-posta (e-mail): yusufaydin@ siirt.edu.tr
}

MAKALE BİLGİSİ

Alınış tarihi 17 Eylül 2019

Düzeltilme tarihi 04 Ekim 2019

Kabul tarihi 06 Ekim 2019

\section{Anahtar Kelimeler:}

Pamuk

Sulama düzeyi

Buharlaşma kabı

Verim tepki etmeni

\begin{abstract}
ÖZ
Bu çalışma, Siirt Üniversitesi, Ziraat Fakültesi deneme alanında, BA440 çeşidi pamuk tohumu kullanılarak yürütülmüştür. Çalışma, damla sulama sistemi kullanılarak, A sınıfı kaptan olan buharlaşmanın $80 \mathrm{~mm}\left(\mathrm{D}_{1}\right)$ ve $120 \mathrm{~mm}\left(\mathrm{D}_{2}\right)$ düzeyine ulaştığında bu miktarların \%50 $\left(\mathrm{I}_{1}\right)$, $\% 75\left(\mathrm{I}_{2}\right)$ ve \%100 $\left(\mathrm{I}_{3}\right)$ "nün sulama suyu olarak uygulanması esasına göre düzenlenmiştir. Konulardan en düşük ve en yüksek verim değerleri $35.4 \mathrm{~kg} \mathrm{da}^{-1}\left(\mathrm{D}_{1} \mathrm{I}_{2}\right)$ ile $59.97 \mathrm{~kg} \mathrm{da}^{-1}\left(\mathrm{D}_{1} \mathrm{I}_{1}\right)$ konularından elde edilirmiştir. Konuların bitki su tüketimleri, $656.2 \mathrm{~mm}\left(\mathrm{D}_{1} \mathrm{I}_{3}\right)$ ile $530.3 \mathrm{~mm}$ $\left(\mathrm{D}_{2} \mathrm{I}_{1}\right)$ arasinda hesaplanırken, konulara uygulanan sulama suyu miktarları $249.9 \mathrm{~mm}\left(\mathrm{D}_{1} \mathrm{I}_{3}\right)$ ile $123.6 \mathrm{~mm}\left(\mathrm{D}_{2} \mathrm{I}_{1}\right)$ arasında gerçekleşmiştir. Yapılan istatistik analizde konular arasındaki fark, önemli bulunmamıştır. Kütlü verimlerden elde edilen randıman değerleri, konularına göre \%41.5 ile \%42.5 arasında, yaprak alanları ise $50.9 \mathrm{~cm}^{2}$ ile $68.1 \mathrm{~cm}^{2}$ arasında değișmiștir. Konuların verim ve evapotranspirasyon değerleri kullanılarak kısıntılı sulama koşullarında pamuk verim-tepki etmeni, $\mathrm{K}_{\mathrm{y}}=1.78$ olarak hesaplanmıştır.
\end{abstract}

\section{ARTICLE INFO}

Received 17 September 2019

Received in revised form 04 October 2019

Accepted 06 October 2019

\section{Keywords:}

Cotton

Irrigation level

Evaporation pan

Yield response factor

\begin{abstract}
This study was carried out in Siirt University, Faculty of Agriculture, experiment area, using BA440 cotton seed. The study arranged on the basis of using the drip irrigation system, application of $50 \%\left(\mathrm{I}_{1}\right), 75 \%\left(\mathrm{I}_{2}\right)$ and $100 \%\left(\mathrm{I}_{3}\right)$ of these amounts as irrigation water when the evaporation from class A pan reaches $80 \mathrm{~mm}\left(\mathrm{D}_{1}\right)$ and $120 \mathrm{~mm}\left(\mathrm{D}_{2}\right)$. The lowest and highest yield values of the treatments were obtained as $35.4 \mathrm{~kg} \mathrm{da}^{-1}\left(\mathrm{D}_{1} \mathrm{I}_{2}\right)$ and $59.97 \mathrm{~kg} \mathrm{da}^{-1}\left(\mathrm{D}_{1} \mathrm{I}_{1}\right)$. The plant water consumption of the treatments was calculated between $656.2 \mathrm{~mm}\left(\mathrm{D}_{1} \mathrm{I}_{3}\right)$ and $530.3 \mathrm{~mm}\left(\mathrm{D}_{2} \mathrm{I}_{1}\right)$, while the amount of irrigation water applied to the subjects was between $249.9 \mathrm{~mm}\left(\mathrm{D}_{1} \mathrm{I}_{3}\right)$ and $123.6 \mathrm{~mm}\left(\mathrm{D}_{2} \mathrm{I}_{1}\right)$. The difference between the subjects was not found significant in the statistical analysis. The ratio of seed and fibre values obtained from treatment's yield were ranged from $41.5 \%$ to $42.5 \%$ and leaf areas ranged from $50.9 \mathrm{~cm}^{2}$ to $68.1 \mathrm{~cm}^{2}$ according to their subjects. Using yield and evapotranspiration values of the subjects, cotton yield-response factor was calculated as $\mathrm{K}_{\mathrm{y}}=1.78$ under deficit irrigation conditions.
\end{abstract}

\section{Giriş}

Dünya pamuk üretiminin ancak \%2-3'lük kısmı ülkemizde üretilmektedir. İklim özelliklerine bağlı olarak, ülkemizde sınırlı bölgelerde yetişmektedir. Yaygın olarak Güneydoğu Anadolu, Akdeniz ve Ege bölgelerinde yetiştirilmektedir. Güneydoğu Anadolu Bölgesi, uygun iklim koşulları nedeniyle Türkiye pamuk üretiminin yaklaşık \%60'ına sahiptir (Karademir ve ark. 2018). Türkiye pamuk üretiminin \%41.97'si Şanlıurfa, \%13.52'si Aydın, \%10.84'ü Hatay, \%8.87'si Diyarbakır, \%6.87 Adana ve \%17.9'u ise diğer illerde yetiştirilmektedir. Ancak üretilen pamuk, talebi karşılayamamaktadır. Tekstil sektörünün 1990 yıllarda gelişmesiyle doğru orantılı olarak pamuk tüketimi de artmış ancak üretimde aynı oranda artış olmamıştır. Pamuk ekim alanlar1 2002 y1lında 721077 ha iken 2017 y1lında \%30'luk azalmayla 501853 hektara düşmüştür. Buna karşın üretim miktarı da aynı yıllarda 2541832 ton'dan 2450000 ton'a gerilemiştir. Üretimdeki bu azalmaya, talep artış1 da eklendiğinde oluşan üretim açığı ithalat yoluyla kapatılmıştır. Pamuk ithalat artışı, 2002-2017 yılları arasında \%56.25 oranında gerçekleşmiştir (ZMO 2018). Tarımsal üretimin en önemli unsuru olan toprak ve su kaynakları, ülkeler ve toplumlar için hayati ve stratejik bir öneme sahiptir. Dünyanın artan nüfusu, hızlı sanayileşme, küresel iklim değişikliği sonucu oluşan küresel 1sınma, hızlı kentleşme gibi faktörler sonucu artan gıda ihtiyacı, tarım arazilerinin tarım dışı kullanımının artması, su kaynaklarının verimli kullanılmaması gibi etmenler, sonlu ve kit olan toprak ve su kaynakları üzerindeki baskıyı 
artırmaktadır. $\mathrm{Bu}$ bakımdan toplumların varlıklarını sürdürebilmeleri ve yaşam standartlarını yükseltebilmeleri, bu iki kaynağın rasyonel kullanımına, işletilmesine ve korunmasına bağlıdır. Tarım alanlarının artırılmasının olanaklı olmadığı günümüzde, birim alandan alınan ürün miktarının artırılması gerekmektedir. $\mathrm{Bu}$ amaçla, modern tarım tekniklerinin kullanımının yanı sıra, kaliteli ve yüksek verim almak için, öncelikle sulama olmak üzere kaliteli tohumluk, gübreleme, ilaçlama gibi kültürel uygulamalar optimum düzeyde yapılmalıdır (Yılmaz ve ark. 2005).

Ülkemizde su kaynaklarının yaklaşık \%70'i tarımsal sulama amaçlı kullanılmakta olup, hızlı nüfus artışı ve sanayileşme gibi nedenlerle bu oran, giderek azalmaktadır (Kanber ve ark. 1994). Tarımda kullanılan sulama suyunda, çeşitli nedenlerle oluşan kısıt, sulama kaynaklı tarımsal kirlilik ve birim miktar suya karşı1ık daha fazla ürün alma isteği, klasik sulama yöntemlerinden daha ziyade yüksek randımanlı sulama yöntemlerini kullanılmasını zorunlu kılmaktadır (Ertek ve Kanber 2000). Damla sulama, pamukta verimin artışına neden olmakta ve erken hasadı teşvik etmektedir (Fereres ve ark. 1985). Bu nedenle kaynak kirliliğinin önüne geçmek ve etkin su kullanımı sağlamak için, geleneksel sulama yöntemleri yerine yersel basınçlı sulama yöntemlerinin kullanılması gittikçe önem kazanmaktadır. Ülkemizde sulanan alanların \%90'dan fazlasında yüzey sulama yöntemleri kullanılmaktadır. Bu alanlarında yaklaşık \%60'ında ise düşük randımanlı olan salma sulama yöntemi kullanılmaktadır. Son zamanlarda sulama teknolojilerinde meydana gelen gelişmeler doğrultusunda damla sulama yöntemi, tarla bitkileri yetiştiriciliğinde yaygın olarak kullanılmaya başlanılmıştır. $\mathrm{Bu}$ yöntemle toprak yüzeyinde daha az alan 1slatıldığından, suyun etkin kullanımının yanı sıra sulama suyundan yüksek oranda tasarruf sağlanmaktadır (Ertek 2001; Dağdelen ve ark. 2005).

Pamuk üretimi, ekonomik faydalarının yanı sıra, ülkenin ve üreticilerin sosyo-ekonomik yapısı üzerinde önemli etkiye sahiptir. Sadece tekstil endüstrisi için ham madde sağlamakla kalmayıp, yă̆ (\%18-24) ve protein (\%20-40) bakımından zengin olması nedeniyle yem ve yağ sanayisine de katk1 sağlamaktadır. Pamuk, sadece yağışla beslenen koşullarda yetiştirilebilmesine karşın, optimum verim için sulama mutlaka gereklidir (Çetin ve Bilgel 2002). Sulama, diğer kültürel uygulamalar ile birlikte yüksek miktarda ve kaliteli pamuk elde etmek için en önemli girdilerden birisidir (Ektiren ve Değirmenci 2018). Kuraklığa dayanıklı bir bitki olarak bilinen pamuk, uygun sulama uygulamaları ile verimde 3-4 kat verim artış1 sağlanabilmektedir (Tekinel ve Kanber 1989). Aşırı sulama, bitkide vejetatif aksamın gelişmesini artırarak verimde azalmaya neden olabileceği gibi, düzensiz ve yetersiz sulama da dökülme oranını artırabilmektedir (Önder ve ark. 2009). Pamuk sulamasında \%30'a kadar olabilecek su kisitı istatistiksel anlamda verimde herhangi bir azalmaya neden olmamaktadır (Tekinel ve Kanber 1979).

$\mathrm{Bu}$ çalışmada, Siirt ekolojik koşullarında farklı sulama düzeylerinin pamuk verimi, su kullanma randımanları ve bazı pamuk kalite parametreleri üzerine olan etkileri incelenmiştir.

\section{Materyal ve Metot}

\subsection{Deneme Alanı topraklarının özellikleri}

Araştırma, Siirt Üniversitesi, Ziraat Fakültesi, Kezer Kampüsü içerisinde, 2018 y1lı üretim sezonunda yürütülmüştür. Kampüs alan1, Siirt merkeze $10 \mathrm{~km}$ uzaklıkta olup, denizden

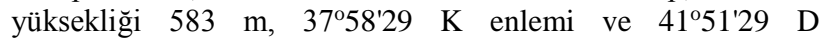
boylamındadır.

Deneme alanı topraklarına ilişkin bazı özellikler Çizelge 1'de verilmiştir. Çizelgenin incelenmesinden görüleceği üzere nötr yada hafif alkali özellikte olup, yüzeyden derine inildikçe kireç oranı artış göstermektedir. Toprak organik madde miktarı oldukça düşük, kumlu killi tın ya da kumlu tın bünyeye sahiptir.

\section{2. İklim Durumu}

Araştırmanın yürütüldüğü Siirt iline ait uzun yıllık meteorolojik veriler Çizelge 2'de verilmiştir.

Siirt ilinde karasal iklim özelliğine sahip olup, mevsimler en belirgin şekilde yaşanmaktadır. Karasal iklimin tipik özellikleri olan yazları sıcak ve kurak, kışları ise daha sert ve yağışlıdır. Yaz aylarında sıcaklık genelde $40^{\circ} \mathrm{C}$ 'ye yakın değerlerde görülmektedir (DMIGGM 2018). En yüksek sıcaklık değerleri Temmuz-Ağustos aylarında $46^{\circ} \mathrm{C}$ 'ye kadar ulaşabilmektedir. Karasal iklimin bir özelliği olarak yaz dönemlerindeki yüksek sıcaklıklara karşın, kış aylarında en düşük sıcaklık $-19.3^{\circ} \mathrm{C}$ 'ye kadar düşebilmektedir. Yıllık yağışların dağılımı da oldukça düzensiz olup, yağışların çoğu, kış aylarında düşmektedir.

Çalışmada tohum materyali olarak BA440 çeşidi pamuk tohumu kullanılmıştır. Güneydoğu Anadolu Bölgesine adapte olmuş olan bu çeşit, geniş adaptasyon yeteneğine ve yüksek verim potansiyeline sahiptir. Bitki boyu orta, odun dalı sayıs1 az ve piramit görünümüne sahiptir. Makinalı hasada uygun bir çeşittir. Yaprakları tüylü görünüme sahip olduğundan emicilere (Empoasca) toleranslıdır ve erkenci bir çeşittir.

\subsection{Sulama Suyu}

Çalışmada kullanılan sulama suyu, deneme alanı etrafinda bulunan ağaçların sulaması için daha önceden alana kapalı sistemle taşınan şebeke suyundan sağlanmıştır. Buradan alınan örneklerde yapılan sulama suyu analiz sonuçları Çizelge 3'de verilmiştir. Buna göre, tuzluluk yönünden sorun oluşturmayan, $\mathrm{C}_{2} \mathrm{~S}_{1}$ sınıfi sulama suyu denemede kullanılmıştır.

Çizelge 1. Araştırma alanı topraklarının bazı özellikleri.

Table 1. Some soil characteristics of the research area.

\begin{tabular}{|c|c|c|c|c|c|c|c|c|}
\hline \multirow{3}{*}{$\begin{array}{l}\text { Toprak } \\
\text { Derinliği } \\
\text { (cm) }\end{array}$} & \multicolumn{8}{|c|}{ Yapilan Analizler } \\
\hline & \multirow{2}{*}{$\mathrm{pH}$} & \multirow{2}{*}{ Toplam Tuz $\left(\mathrm{dS} \mathrm{m}^{-1}\right)$} & \multirow{2}{*}{ Kireç (\%) } & \multicolumn{3}{|c|}{ Bünye (\%) } & \multirow{2}{*}{ Organik Madde $(\mathrm{OM})(\%)$} & \multirow{2}{*}{ SAR } \\
\hline & & & & Kil & Silt & Kum & & \\
\hline $0-30$ & 7.43 & 0.13 & 2.01 & 22.16 & 24.00 & 53.84 & 1.58 & 1.83 \\
\hline $30-60$ & $\begin{array}{l}\text { Hafif Alkali } \\
7.80\end{array}$ & $\begin{array}{c}\text { Tuzsuz } \\
0.09\end{array}$ & $\begin{array}{c}\text { Az kireçli } \\
13.89\end{array}$ & \multicolumn{3}{|c|}{ Kumlu-Killi Tın } & $\begin{array}{c}\mathrm{Az} \\
0.76\end{array}$ & \\
\hline $30-60$ & Hafif Alkali & Tuzsuz & Kireçli & \multicolumn{3}{|c|}{ Kumlu-Killi Tın } & Çok az & 4.60 \\
\hline $60-90$ & $\begin{array}{l}7.00 \\
\text { Nötr }\end{array}$ & $\begin{array}{c}0.22 \\
\text { Tuzsuz }\end{array}$ & $\begin{array}{c}27.97 \\
\text { Cok kirecli }\end{array}$ & 18.06 & $\begin{array}{l}10.00 \\
\text { umlu tin }\end{array}$ & 71.84 & $\begin{array}{c}0.60 \\
\text { Cok az }\end{array}$ & 2.52 \\
\hline
\end{tabular}


Çizelge 2. Siirt iline ait uzun y1llık meteorolojik veriler (1938-2017).

Table 2. Long-term meteorological data of Siirt province (1938-2017).

\begin{tabular}{|c|c|c|c|c|c|c|c|}
\hline Parametre & $\begin{array}{l}\text { Max. Sic. } \\
\left({ }^{\circ} \mathrm{C}\right)\end{array}$ & $\begin{array}{l}\text { Min. Sic. } \\
\left({ }^{\circ} \mathrm{C}\right)\end{array}$ & $\begin{array}{c}\text { Ort. Nisbi nem, } \\
(\%)\end{array}$ & $\begin{array}{l}\text { Top. Yağış ort. } \\
(\mathrm{mm})\end{array}$ & $\begin{array}{l}\text { Max. Yağgış } \\
(\mathrm{mm})\end{array}$ & $\begin{array}{l}\text { Ort. Buhar. } \\
(\mathrm{mm})\end{array}$ & $\begin{array}{c}\text { Ort. Güneş. Sür. } \\
\text { (saat) }\end{array}$ \\
\hline Rasat Süresi (Y1l) & 79 & 79 & 78 & 78 & 79 & 79 & 57 \\
\hline Ocak & 19.7 & -19.3 & 71.9 & 34.6 & 53.4 & 12.0 & 3.6 \\
\hline Şubat & 20.6 & -16.5 & 67.1 & 29.4 & 53.2 & & 4.4 \\
\hline Mart & 28.5 & -13.3 & 62.0 & 24.1 & 63.0 & 33.0 & 5.4 \\
\hline Nisan & 32.9 & -4.1 & 58.0 & 22.4 & 71.4 & 84.0 & 6.5 \\
\hline Mayıs & 36.2 & 2.0 & 50.7 & 21.2 & 68.1 & 186 & 9.0 \\
\hline Haziran & 40.2 & 8.2 & 34.6 & 15.5 & 16.7 & 284.8 & 11.7 \\
\hline Temmuz & 44.4 & 13.1 & 27.4 & 13.5 & 22.2 & 368.0 & 12.2 \\
\hline Ağustos & 46.0 & 14.4 & 26.4 & 13.3 & 12.2 & 351.8 & 11.4 \\
\hline Eylül & 39.9 & 8.5 & 31.2 & 14.4 & 37.5 & 254.3 & 9.9 \\
\hline Ekim & 36.6 & 0.3 & 46.7 & 49.7 & 70.8 & 137.6 & 7.2 \\
\hline Kasım & 25.8 & -14.1 & 62.4 & 82.5 & 102.9 & 53.0 & 5.2 \\
\hline Aralık & 24.3 & -14.6 & 70.6 & 94.5 & 71.8 & 13.1 & 3.6 \\
\hline Yillik & 46 & -19.3 & 50.8 & 719.8 & 102.9 & 1753.6 & 7.5 \\
\hline
\end{tabular}

Çizelge 3. Deneme alanındaki kuyunun sulama suyu analizi.

Table 3. Irrigation water analysis of well in experimental area.

\begin{tabular}{|c|c|c|c|c|c|c|c|c|c|c|c|c|}
\hline \multirow{2}{*}{ Su Kaynağ } & \multirow{2}{*}{$\begin{array}{c}\text { EC } \\
\left(\mathrm{dS} \mathrm{m}{ }^{-1}\right)\end{array}$} & \multirow{2}{*}{$\mathrm{pH}$} & \multicolumn{4}{|c|}{ Katyonlar $\left(\mathrm{me} \mathrm{l}^{-1}\right)$} & \multicolumn{4}{|c|}{ Anyonlar $\left(\mathrm{me} \mathrm{l}^{-1}\right)$} & \multicolumn{2}{|c|}{ Sulama suyu } \\
\hline & & & $\mathrm{Ca}$ & $\mathrm{Na}(\%)$ & $\mathrm{Mg}$ & $\mathrm{K}$ & $\mathrm{CO}_{3}$ & $\mathrm{HCO}_{3}$ & $\mathrm{Cl}$ & $\mathrm{SO}_{4}$ & SAR & Sinıfi \\
\hline $\begin{array}{l}\text { Şebeke } \\
\text { suyu }\end{array}$ & 0.410 & 7.68 & 2.68 & 0.92 & 1.42 & 0.04 & 0.67 & 2.22 & 0.58 & 1.60 & 0.64 & $\mathrm{C}_{2} \mathrm{~S}_{1}$ \\
\hline
\end{tabular}

\subsection{Sulama Konulart}

Sulama suyu miktarı, deneme alanına yerleştirilen Class A Pan buharlaşma kabından elde edilen açık su yüzü buharlaşma değerleri (D), $80 \mathrm{~mm}$ ve $120 \mathrm{~mm}$ 'ye ulaştığında bu miktarların (I) $\% 50, \% 75$ ve $\% 100$ ' ünün sulama suyu olarak uygulanmas 1 esasına göre düzenlenmiştir.

Sulama aralıkları ana parsellere (D), sulama düzeyleri (I) ise alt parsellere yerleştirilmiş olup, sulama suyunun hesaplanmasında, Eşitlik 1'den yararlanılmıştır.

$$
\mathrm{IR}=\mathrm{I} \times \mathrm{E}_{0} \times \mathrm{A} \times \mathrm{C}
$$

Eşitlikte, IR, sulama suyunu; I, sulama düzeyini; $E_{0}$, sulama aralığındaki yığışımlı buharlaşma miktarını (CAP), mm; A, alan $\left(\mathrm{m}^{2}\right)$ ve C ise, ağaçlar tarafından örtülen alanı (\%) göstermektedir. Örtülen alan \%'sinin bulunmasında ise, Eşitlik 2'den yararlanılmıştır (Ertek ve Kanber 2001).

$$
\mathrm{C}=\stackrel{a}{a} \times 100
$$

Eşitlikte; a, bitki taç genişliği $(\mathrm{cm})$; b: sıra aralığını $(\mathrm{cm})$ ifade etmektedir.

Her bir deneme konusuna ilişkin su tüketimi $\left(\mathrm{ET}_{\mathrm{c}}\right)$ değerlerinin hesaplanmasında Howell ve ark. (1986) tarafindan önerilen "Su Bütçesi” yaklaşımından yararlanılmıştır (Eşitlik 3).

$$
\mathrm{ET}_{\mathrm{c}}=\mathrm{I}+\mathrm{P}+\mathrm{C}_{\mathrm{p}}-\mathrm{D}_{\mathrm{p}} \pm \mathrm{R}_{\mathrm{f}} \pm \Delta \mathrm{S}
$$

Eşitlikte, $\mathrm{P}$ değeri, yağışı; $\mathrm{C}_{\mathrm{p}}$, kılcal yükselişle kök bölgesine giren su miktarını; $D_{p}$, sulama veya yağıştan sonra meydana gelen derine süzülme kayıplarını; $\mathrm{R}_{\mathrm{f}}$, deneme parsellerine giren veya çıkan yüzey akış miktarlarını; $\Delta \mathrm{S}$ ise kök bölgesindeki toprak su değişimini temsil etmektedir. Eşitlikteki tüm birimler, mm boyutundadır. Çalışma, taban suyunun düşük olduğu alanda yürütüldüğünden kılcal yükseliş sıfır alınmıştır. Toprak suyu değişimi, her konuda $90 \mathrm{~cm}$ derinliğindeki toprak profilinin $30 \mathrm{~cm}$ katmanlarında gravimetrik yöntemle belirlenmiştir. Sulamada, $41 \mathrm{~s}^{-1}$ debi ve $0.33 \mathrm{~m}$ damlatıcı aralığına sahip, $16 \mathrm{~mm}$ çapında yerli üretim damlatıcı lateraller kullanılmıştır.

\subsection{Deneme deseni}

Konular, tesadüf bloklarında bölünmüş parseller deneme deseni ile dört yinelemeli olarak arazide konumlandırılmıştır. Çalışmada; ana parseller sulama aralığ 1 ve alt parseller sulama düzeyini oluşturmaktadır. Her bir deneme parseli, $6 \mathrm{~m}$ x $2.8 \mathrm{~m}$ boyutlarında olup, $0.70 \mathrm{~m}$ sıra aralığı ve $0.15-0.20 \mathrm{~m}$ sıra üzeri dört sıra bitki ekilmiştir. Ölçme ve gözlemler, kenar tesirlerinden arındırmak amacıyla deneme parselinin 2 . ve 3. sıralarından alınmıştır.

\subsection{Verim Tepki Etmeninin $\left(K_{y}\right)$ Belirlenmesi}

Yürütülen bu çalışmada, pamuk sulama-verim ilişkisi ve kalite parametrelerinin yanı sıra, bitkilerin suya olan tepkilerini belirleyen verim-tepki etmeni $\left(\mathrm{K}_{\mathrm{y}}\right)$ de belirlenmeye çalışılmıştır. $\mathrm{Bu}$ amaçla Köksal ve ark. (2001) tarafından verilen yaklaşımlar kullanılarak, pamukta Oransal Evapotranspirasyon Açığı ile Oransal Verim Azalışları arasındaki ilişkiyi açıklayan verim tepki etmeni kestirilmiştir.

$$
\left(1-\mathrm{Y} / \mathrm{Y}_{\mathrm{m}}\right)=\mathrm{K}_{\mathrm{y}}\left(1-\mathrm{ET} / \mathrm{ET}_{\mathrm{m}}\right)
$$

Eşitlikte; $Y$ ve $Y_{m}$, gerçek ve maksimum verimleri; ET ve $\mathrm{ET}_{\mathrm{m}}$, gerçek ve maksimum su tüketimleri; $\mathrm{K}_{\mathrm{y}}$ ise verim tepki etmenini göstermektedir.

Deneme alanının ekime hazırlanmasından sonra tohumlar, 15.05.2018 tarihinde mibzerle ekimi yapılmış ve ekimle birlikte deneme alanının tamamına $20 \mathrm{~kg} \mathrm{da}^{-1}$ saf azot hesabına uygun 
olarak $30 \mathrm{~kg} 15 \times 15 \times 15$ ile $15 \mathrm{~kg} 20 \times 20 \times 0$ kompoze gübreler bütün konulara uygulanmıştır. Buna ilaveten üst gübre olarak 8 $\mathrm{kg} \mathrm{da}^{-1}$ saf N uygulamak üzere \%21 Amonyum Sülfat gübresi, sulama suyu ile birlikte 2'ye bölünerek 07.07.2018 tarihinde uygulanmıştır (Karademir 2018). Ekimi yapılan tohumlarda düzenli çıkışların olmadığı lokal alanlarda tohum aşılaması yapılmış ve sulama sistemi monte edilerek Class A Pan buharlaşma kabı deneme alanına yerleştirilmiştir. Sulama uygulamalarına çiçeklenme öncesi dönemde başlanılarak, kozaların \%10 açıldığı dönemde sonlandırılmıştır. Uygulanan sulama suyu miktarı, değişik zaman aralıklarında arazi içerisinde damlatıcı debi testi yapılarak denetlenmiş ve konulara uygulanan sulama suyu miktarları, ortalama debi hesabıyla vanaların zamana bağlı olarak çalıştırılmasıyla belirlenmiştir. Denemede hasat işlemi, 2 aşamalı olarak tamamlanmıştır. Hasat olgunluğuna ulaşıldığında ve kozaların $\% 60-70$ açıldığ dönemde elle ilk hasat yapılmış olup, kalanların tamamı açıldığında hasat işlemi tamamlanmıştır.

\subsection{Pamuk kütlü verimi $\left(\mathrm{kg} d a^{-1}\right)$}

Bitkiler hasat olgunluğuna ulaştığında oluşturulan konularda 4 sıradan oluşan bitki sıraları, birinci ve dördüncü sıralar kenar tesirlerini ortadan kaldırmak için hasat edilmeyip ortadaki 2 . ve 3. sıralardaki $8.4 \mathrm{~m}^{2}$ lik (6 m x $1.4 \mathrm{~m}$ ) alandaki bitkilerden hasat yapılmış ve toplanan kütlü pamuk tartılarak dekar'a kg olarak hesaplanmıştır.

\subsection{Istatistik Analizler}

Denemeden elde edilen verim ve kalite parametreleri JMP istatistik paket programı kullanılarak değerlendirilmiştir.

\section{Bulgular ve Tartışma}

Deneme alanı, özellikleri Çizelge 1'de verilen, organik maddesi oldukça düşük ağırlıklı olarak kumlu-killi-tın toprak bünyesi ve üst toprak derinliği fazla olmayan bir yapıya sahiptir. Toprak organik madde oranı \%0.6 ile \%1.6 arasında değişmektedir. Toprak derinliğinin artışına paralel olarak kireç oranı artı̧̧ göstermektedir.

\subsection{Fenolojik gözlemler}

Denemenin yürütüldüğü 2018 yılında ekim-hasat dönemleri arasındaki fenolojik gözlemler takip edilmiştir. Arazi hazırlanmasından sonra 15 Mayıs tarihinde ekimi yapılan tohumlar 20 Mayıs tarihinde çıkışlara başlamış ve 10 Temmuz tarihinde çiçeklenme oran $\% 50$ düzeyine ulaşmıştır. Denemede ilk koza açılışı 16 Ağustos tarihinde gerçekleşmiştir. Pamuk ekiminin yapıldığ 15 Mayıs döneminden 2. el hasadının yapıldığı 16 Ekim tarihleri arasında 154 günlük bir yetişme dönemi geçirmiştir.

\subsection{Verim}

Denemeden elde edilen verim Çizelge 4'de verilmiştir. Verim değerleri tesadüf bloklarında bölünmüş parseller deneme desenine göre varyans analizine tabi tutulmuştur. Varyans analizi sonuçlarına göre istatistiksel olarak önemli çıkan uygulamalar LSD testi ile karşılaştırılmıştır. Önemli çıkmayan tüm uygulamalar ise gruplandırılmamıştır.

\subsection{Bitki Su Tüketimleri}

Konuların bitki su tüketimi değerleri hesaplanırken, bitki kök bölgesindeki toprak suyu değişimi, uygulanan sulama suyu miktarları ve yağış miktarları dikkate alınmış ve hesaplanan bitki su tüketimi değerleri Çizelge 5'de gösterilmiştir. Hesaplamada gelişme mevsimi boyunca düşen yağışın tümü, miktar ve sıklık nedeniyle etkili yağış kabul edilmiştir. Konuların su tüketimi değerleri $535.6 \mathrm{~mm}$ ile $656.2 \mathrm{~mm}$ arasında değişmiştir. ET değerlerinin yüksek miktarda gerçekleşmesi, vejetasyon dönemi içerisinde oluşan yağışın fazla olmasından kaynaklanmaktadır. Bitki su tüketimi, yağışın az ve toprak kalınlığının fazla olduğu kurak ve yarı kurak bölgelerde ve sulamanın yapılmadığı koşullarda, yağışa eşit olduğu, Şener (1993) tarafindan belirtilmektedir. Bu nedenle, çalışmada su tüketim değerlerindeki farklılık ve yükseklik, yağış rejiminde oluşan dalgalanmadan kaynaklanmaktadır.

Çizelge 4. Sulama konularına göre verim değerleri.

Table 4. Yield values according to irrigation treatments.

\begin{tabular}{cccccc}
\hline Konular & $\mathbf{R}_{\mathbf{1}}$ & $\mathbf{R}_{\mathbf{2}}$ & $\mathbf{R}_{\mathbf{3}}$ & $\mathbf{R}_{\mathbf{4}}$ & Ort. \\
\hline $\mathrm{D}_{1} \mathrm{I}_{1}$ & 37.17 & 73.19 & 69.10 & 60.42 & 59.97 \\
$\mathrm{D}_{1} \mathrm{I}_{2}$ & 31.18 & 57.83 & 38.55 & 43.69 & 42.81 \\
$\mathrm{D}_{1} \mathrm{I}_{3}$ & 33.73 & 68.67 & 56.81 & 68.13 & 56.84 \\
$\mathrm{D}_{2} \mathrm{I}_{1}$ & 39.04 & 72.72 & 80.12 & 54.76 & 61.66 \\
$\mathrm{D}_{2} \mathrm{I}_{2}$ & 71.08 & 62.77 & 37.65 & 60.48 & 58.00 \\
$\mathrm{D}_{2} \mathrm{I}_{3}$ & 47.59 & 59.76 & 59.64 & 34.28 & 50.32 \\
\hline
\end{tabular}

Çizelge 5. Sulama konularına göre evapotranspirasyon (ET) bileşenleri.

Table 5. Evapotranspiration (ET) components of irrigation treatments.

\begin{tabular}{cccccc}
\hline Konular & Kütlü Verim $\left(\mathrm{kg} \mathrm{da}^{-1}\right)$ & $\mathrm{IR}(\mathrm{mm})$ & $\mathrm{P}(\mathrm{mm})$ & $\mathrm{D}_{\mathrm{p}}(\mathrm{mm})$ & $\Delta \mathrm{S}(\mathrm{mm})$ \\
\hline $\mathrm{D}_{1} \mathrm{I}_{1}$ & 59.97 & 124.93 & 363.1 & 0.0 & 47.60 \\
$\mathrm{D}_{1} \mathrm{I}_{2}$ & 35.42 & 187.39 & 363.1 & 0.0 & 52.60 \\
$\mathrm{D}_{1} \mathrm{I}_{3}$ & 56.84 & 249.86 & 363.1 & 0.0 & 42.80 \\
$\mathrm{D}_{2} \mathrm{I}_{1}$ & 43.63 & 123.61 & 363.1 & 0.0 & 635.63 \\
$\mathrm{D}_{2} \mathrm{I}_{2}$ & 58.00 & 185.41 & 363.1 & 0.0 & 43.60 \\
$\mathrm{D}_{2} \mathrm{I}_{3}$ & 50.32 & 247.21 & 363.1 & 0.0 & 46.60 \\
\hline
\end{tabular}




\subsection{Pamuk Sulama suyu-Verim ve Sulama suyu-bitki su tüketimleri (ET) İlişkisi}

Çalışma yılında konulardan elde edilen verim değerleri ile sulama suyu arasındaki ilişkinin varlığı ve düzeyi de araştırılmıştır. Bu amaçla konuların verim değerleri ile sulama suyu arasındaki birlikte değişim incelenmiş ve elde edilen ilişki grafiği Şekil 1'de verilmiştir.

Konuların verim ve sulama suyu değerleri bakımından yapılan karşılaştırmada, aralarındaki ilişkinin önemli olmadığ ya da çok düşük olduğu $(r=0.32, n=6)$ görülmektedir. Benzer olarak, bitki su tüketimleri ile verim değerleri arasında yapılan karşılaştırmada, ET ile verim arasında ikinci dereceden polinomial bir ilişkinin olduğu $(r=0.24, n=6)$ belirlenmiştir. Ancak varyans analiz sonuçlarına bakıldığında konu ortalamaları arasındaki farklılık istatistiksel olarak önemli bulunmamıştır. İlişki düzeyi ve ölçülen değer (n) sayısının küçük olması, bu ilişkinin istatistik anlamda önemli olmadığını göstermektedir. $\mathrm{Bu}$ durum, verilerin tek yıllık olmasiyla ilişsilendirilebilir. Çalışmanın ardıl yıllarda tekrarlanması ve ölçülen parametrelerin sayılarının artırılması, ilişkinin daha anlamlı bulunmasına katkı sağlayacaktır.

\subsection{Pamuk kalite analizleri}

Deneme konularından yönteminde açıklandığı üzere hasat edilen kütlü pamuk verimleri, tartılarak parsel verimleri belirlenmiş ve dekara $\mathrm{kg}$ olarak verim değerlerine dönüştürülmüştür. İlk hasatta her bir parselden elde edilen kütlü verimlerden $1 \mathrm{~kg}$ kütlü örneği alınarak çırçır randımanı, daha sonra laboratuvar koşullarında lif kalite analizleri yaptırılmıştır.

Verim ve kalite parametreleri bakımından konular arasındaki farklılıkların belirlenmesi amaciyla varyans analizleri
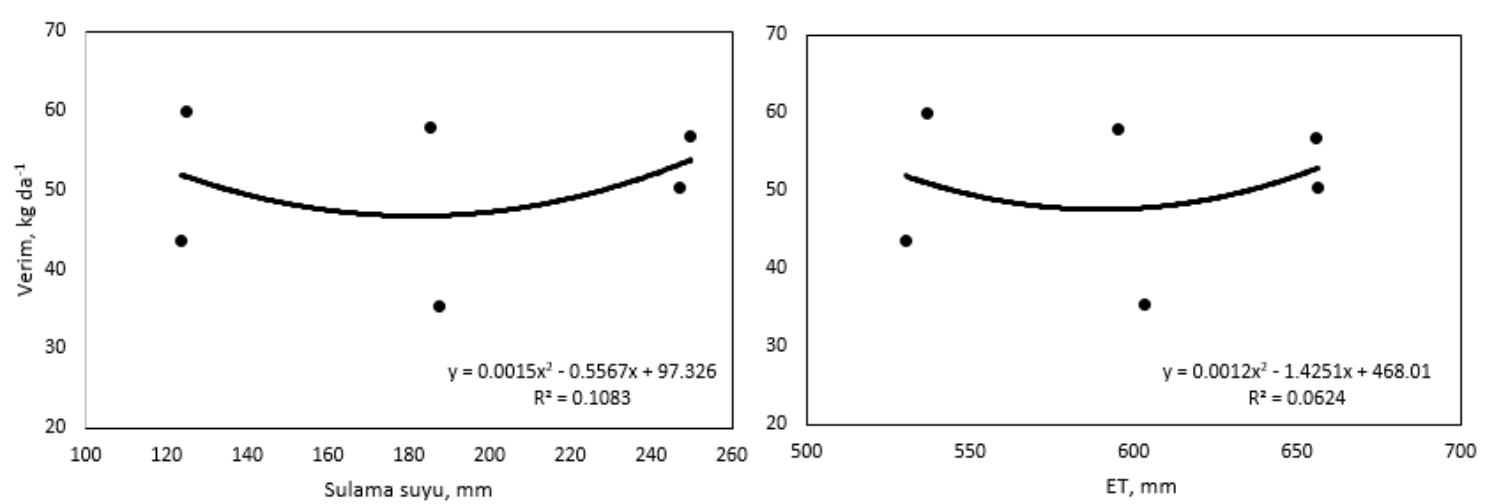

Şekil 1. Sulama suyu ve bitki su tüketiminin (ET) verim ile ilişkisi.

Figure 1. Relationship between irrigation water and plant water consumption (ET) and yield.

Çizelge 6. Konulardan elde edilen ürünlerin kalite analizlerinin ortalama değerleri.

Table 6. The average values of the quality analysis of the products obtained from the treatments.

\begin{tabular}{cccccccccccccc}
\hline Konular & $\begin{array}{c}\text { Rand. } \\
(\%)\end{array}$ & Mic & Mat & UI & Str & Elg. & Rd & b+ & $\begin{array}{c}\text { Nem } \\
(\%)\end{array}$ & $\begin{array}{c}\text { Ort. } \\
\text { Uzunluk }\end{array}$ & $\begin{array}{c}\text { SF } \\
(\%)\end{array}$ & $\begin{array}{c}\text { SCI } \\
\left(\mathrm{cm}^{2}\right)\end{array}$ \\
\hline $\mathrm{D}_{1} \mathrm{I}_{1}$ & 41.5 & 4.3 & 0.9 & 82.7 & 28.7 & 5.5 & 75.3 & 9.4 & 7.7 & 27.9 & 9.4 & 126.8 & 64.7 \\
$\mathrm{D}_{1} \mathrm{I}_{2}$ & 42.0 & 4.5 & 0.9 & 81.4 & 28.7 & 5.6 & 75.2 & 9.7 & 7.4 & 27.5 & 10.2 & 117.8 & 62.6 \\
$\mathrm{D}_{1} \mathrm{I}_{3}$ & 41.6 & 4.0 & 0.9 & 82.5 & 29.7 & 5.6 & 75.2 & 9.7 & 7.4 & 27.8 & 10.6 & 131.3 & 56.2 \\
$\mathrm{D}_{2} \mathrm{I}_{1}$ & 41.9 & 4.8 & 0.9 & 82.9 & 29.7 & 5.6 & 75.0 & 9.8 & 7.5 & 27.7 & 8.5 & 126.3 & 57.0 \\
$\mathrm{D}_{2} \mathrm{I}_{2}$ & 42.5 & 4.6 & 0.9 & 83.2 & 31.4 & 5.7 & 73.1 & 9.8 & 7.6 & 28.1 & 8.5 & 133.5 & 68.1 \\
$\mathrm{D}_{2} \mathrm{I}_{3}$ & 42.2 & 4.6 & 0.9 & 82.9 & 30.4 & 5.5 & 73.7 & 9.5 & 7.8 & 28.0 & 8.5 & 128.5 & 50.9 \\
\hline $\mathrm{LSD}$ & ÖD & ÖD & ÖD & ÖD & ÖD & ÖD & ÖD & ÖD & ÖD & ÖD & ÖD & ÖD & ÖD \\
\hline
\end{tabular}

Rand: randıman, Mic: incelik, Mat: olgunluk, UI: Üniformite indexi, Str: lif mukavemeti, Elg: esneme özelliği, Rd: parlaklık, +b: sarılık oranı, SF: kısa lif yüzdesi, SCI: iplik eğrilebilirlik indexi, YA: yaprak alanı, ÖD: önemli değil. 


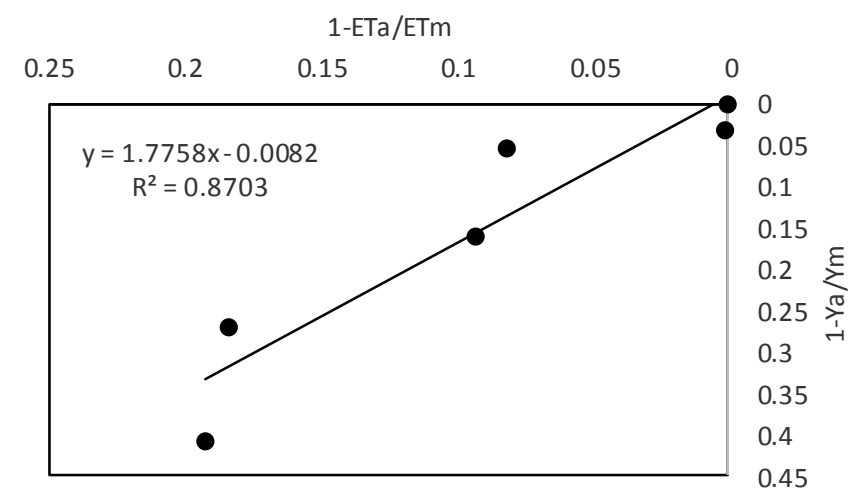

Şekil 2. Pamukta verim-tepki etmeni.

Figure 2. Yield response factor of cotton.

sulama ile sulanan pamukta $\mathrm{K}_{\mathrm{y}}$ katsayısının 1.2 olarak, Ertek ve Kanber (2003), Çukurova bölgesi Aşağı Seyhan Ovası koşullarında $\mathrm{K}_{\mathrm{y}}$ faktörünün 0.38-0.84 arasında değiştiğini ifade etmektedirler. Çalışmadan elde edilen bulgularla, araştırmacıların bulguları birbirine yakın değerler almakla birlikte, farklılıkların da olduğu görülmektedir. Aralarındaki ayrışma, çalışılan coğrafik bölgeden ve iklim koşullarından kaynaklandığ 1 gibi, yukarıda sayılan ve $\mathrm{K}_{\mathrm{y}}$ faktörünü etkileyen etmenlerdeki farkl1liklara atfedilebilir.

\section{Sonuç ve Öneriler}

Konulardan elde edilen verim değerleri arasında yapılan istatistik analizde, konular istatistiksel anlamda önemli bulunamazken, en düşük ve en yüksek verim değerleri 35.4 $\mathrm{kg} \mathrm{da}^{-1} \quad\left(\mathrm{D}_{1} \mathrm{I}_{2}\right)$ ile $59.97 \mathrm{~kg} \mathrm{da}^{-1} \quad\left(\mathrm{D}_{1} \mathrm{I}_{1}\right)$ konularından elde edilmiştir. Çalışmada verim değerleri, oldukça düşük gerçekleşmiştir. Önder ve ark. (2009) yaptıkları çalışmada pamuk verimini 154 ile $542 \mathrm{~kg} \mathrm{da}^{-1}$ arasında belirlerken, Ertek ve Kanber (2002) 96-422 $\mathrm{kg} \mathrm{da}^{-1}$ arasinda, Ektiren ve Değirmenci (2018) bu değerleri konulara göre değişmekle beraber $481.1 \mathrm{~kg} \mathrm{da}^{-1}$ ile $106.3 \mathrm{~kg} \mathrm{da}^{-1}$ arasında bulmuşlardır. Araştırma bulguları ile arasındaki uyumsuzluk, çalışmanın yürütüldüğü deneme alanı toprak koşullarına atfedilmektedir. $\mathrm{Bu}$ durumda sulama aralığ 1 olarak, yığışımlı buharlaşma miktarının 80 mm'ye ulaştığı sulama aralığında $\left(D_{1}\right)$ ve buharlaşma miktarının \% 50'sinin kullanıldığı (I 1 ) konusu $\left(\mathrm{D}_{1} \mathrm{I}_{1}\right)$ önerilebilir.

Deneme konularında bitki su tüketimleri $656.2 \mathrm{~mm}\left(\mathrm{D}_{1} \mathrm{I}_{3}\right)$ ile $530.3 \mathrm{~mm}\left(\mathrm{D}_{2} \mathrm{I}_{1}\right)$ arasında hesaplanırken, konulara uygulanan sulama suyu miktarları $249.9 \mathrm{~mm}\left(\mathrm{D}_{1} \mathrm{I}_{3}\right)$ ile $123.6 \mathrm{~mm}\left(\mathrm{D}_{2} \mathrm{I}_{1}\right)$ arasında gerçekleşmiştir. Yapılan istatistik analizde konular arasındaki fark, önemli bulunmamıştır.

\section{Kaynaklar}

Aydın Y (2004) Antepfistığında farklı su ve azot düzeylerinin verim ve periyodisite üzerine etkileri. Doktora Tezi, Çukurova Üniversitesi, Fen Bilimleri Enstitüsü, Adana.

Aydın Y, Mikail N, Pakyürek M, Saltuk B, Seven M (2017) Water-yield relationship of Zivzik Pomogranate under deficit irrigation condition. Scientific Papers. Series E. Land Reclamation, Earth Observation \& Surveying, Environmental Engineering Vol. VI, 2017.
Çetin Ö, Bilgel L (2002) Effect of different irrigation methods on shedding and yield of cotton. Agricultural Water Management 54: 1-15.

Dağdelen N, Yılmaz E, Sezgin F, Baş S (2005) Aydın ovası koşullarında Yağmurlama sulama yöntemiyle sulanan pamuğun suverim ilişkileri. Adnan Menderes Üniversitesi Ziraat Fakültesi Dergisi 2(1): 29-38.

DMIGM (2018) Web Sayfası. https://www.mgm.gov.tr/veridegerlendirme/il-ve-ilceleristatistik.aspx?k=A\&m=SIIRT. Erişim 06 Aralık 2018.

Doorenbos J, Kassam AH (1986) Cotton. in: Yield response to water. Irrigation and Drainage Paper 33, Rome, pp. 88-92.

Ektiren Y, Değirmenci H (2018) Kısıntılı Sulama uygulamalarının Pamukta (Gossipium hirsitum L.) Yaprak Bitki Besin Elementlerine Etkisi. Kahramanmaraş Sütçü İmam Üniversitesi Tarım ve Doğa Dergisi 21(5): 691-698.

Ertek A, Kanber R (2000) Damla sisteminde farklı sulama programlarının Pamuk bitkisinin değişik toprak katmanlardaki su tüketimine ve kök gelişimine etkilerinin belirlenmesi. Turkish Journal of Agriculture and Forestry 24(2): 283-291.

Ertek A (2001) Damla sulama yönteminin pamuk sulamasinda Topraktaki tuz dağılımına etkileri. Yüzüncü Damla sulama yönteminin pamuk sulamasında Topraktaki tuz dağılımına etkileri. Yüzüncü Y1l Üniversitesi, Ziraat Fakültesi, Tarım Bilimleri Dergisi 12(2): 21-31.

Ertek A, Kanber R (2002) Damla yöntemiyle sulanan pamukta farklı sulama programlarının kalite özelliklerine etkileri. Kahramanmaraş Sütçü İmam Üniversitesi, Fen ve Mühendislik Dergisi 5(1): 118129.

Ertek A, Kanber R (2003) Effects of different irrigation programmes on the boll number and shadding percentage and yield of cotton. Agricultural Water Management 60(1): 1-11.

Fereres E, Cueves R, Orgaz F (1985) Drip Irrigation of Cotton in Southern Spain. Proceeding. of the Third International Drip Irrigation Congess. Ed. by American Society of Association Executives (1): 371-374.

Howell TA, Musick JT, Tolk JA (1986) Canopy Temperature of Irrigated Winter Wheat. Trans. American Society of Association Executives 29(6): 1692-1699.

Kanber R, Tekinel O, Baytorun N, Kumova Y, Alagöz T, Önder S, Köksal H, Gencer O, Koç MK, Diker K, Gencoğlan C (1991) The opportunuties of irrigation interval and water consumption of cotton in determining from water surface evaporation under Harran Plain. Çukurova University. Agriculture Faculty. GAP Research, review and development project No: 5.3.1, Adana, pp. 38. 
Kanber R, Yazar A, Diker K, Ünlü M, Sezen S (1994) Bitki üretim fonksiyonlarının eldesinde çizgi kaynaklı yağmurlama sistemlerinin kullanılması. Çukurova Üniversitesi Ziraat Fakültesi Dergisi 9(1): 133.

Karademir Ç (2018) Yüzyüze görüşmeler.

Karademir E, Karademir Ç, Arslan D, Önder Uçar Ö (2018) Determination of some physiological Properties of Modern Cotton Varieties. International Conferance on Agriculture, Forest, Food Sciences and Technologies, Çeşme-İzmir/Turkey. s. 735-742.

Köksal H, Tarı AF, Çakır R, Kanber R, Ünlü M (2001) Su-Verim İlișkileri (Değiștirilmiș 2. Baskı) [Water-Yield Relationships (Revised 2nd Edition)]. Köy Hizmetleri Ana Projesi (435-1). Konya. s. 87.

Önder D, Akışcan Y, Önder S, Mert M (2009) Effect of Different water level on cotton yield and yield components. African Journal of Biotechnology 8(8): 1536-1544.

Şener S (1993) Sulama Teknolojisinde Yeni Gelişmeler. Köy
Hizmetleri Genel Müdürlüğü, APK Dairesi Başkanlığı, Toprak ve Su Kaynakları Araştırma Şube Müdürlüğü, Yayın No: 76, Tarsus, s. 171.

Tekinel O, Kanber R (1979) Çukurova koșullarında Kısıntılı su uygulama durumunda Pamuğun su tüketimi ve verimi. Tarsus Bölge Toprak-Su Araştırma Enstitüsü Müdürlüğü Yayınları Genel Yayin No: 98, Rapor No: 48, s. 39.

Tekinel O, Kanber R (1989) Pamuk Sulamasının Genel İlkeleri. Çukurova Üniversitesi Ziraat Fakültesi Yardımcı Ders Kitapları Yayın No: 18, Adana, s. 56.

Yılmaz E, Dağdelen N, Sezgin F, Gürbüz T (2005) Aydın Koșullarında Farklı sulama yöntemleri ve sulama programlarının pamukta kütlü kalitesi üzerine etkisi. Adnan Menderes Üniversitesi Ziraat Fakültesi Dergisi 2(1): 17-22.

ZMO (2018) ZMO Pamuk Raporu-2018 http://www.zmo.org.tr/genel/bizden_detay.php?kod= 30467 \&tipi $=17 \&$ sube $=0$. Erisim 04 Subat 2019. 